\title{
SYNTHESIS OF POLYANILINE IN PRESENCE OF LOW MAGNETIC FIELD, ITS STRUCTURE AND ELECTRICAL PROPERTIES
}

\author{
Department of Physics, Institute of Science, Civil Lines, Nagpur, \\ Applied Physics Department, St. Vincent Pallotti College of Engineering and Technology, \\ Nagpur-441 108, India; nafdeyrenuka@yahoo.co.in
}

Received: March 03, 2008

\begin{abstract}
Polyaniline is synthesized chemically under the influence of low magnetic field of intensity $1 \mathrm{KGauss}$. The effect of magnetic field during the synthesis process causes enhancement of electrical conductivity by two orders of magnitude. This increased electrical conductivity depends on the polymer chain ordering, as well as structure and morphology of the reported polymer.
\end{abstract}

Key words: polyaniline, chemical polymerization, low magnetic field, electrical conductivity

\section{Introduction}

The capability of conjugated polymers to act like inorganic semiconductors is broadly known. Many of semiconducting devices like p-n Diode, Schottky Diode, LED's and Photovoltaic Cell are constructed using these polymers. The efficiency of a device based on conjugated polymers is substantially lower and thus renders putting them into practical use impossible. Low efficiency of such devices is inter alia due to the lack of order in polymeric materials, which is necessary to obtain proper electrical conduction.

Magnetic field effect (MFE) on the kinetics of chemical reactions has been studied for a long time. The overall change of yield and kinetics of chemical and related physical processes due to the effect of a static magnetic field has been studied by few researchers. Mori et al. [1] found an increase of the initial rate and yield of radiationinduced polymerization of acrylonitrile when the reaction was carried out in an increasing magnetic field from 0 to $0.5 \mathrm{~T}$ at $77 \mathrm{~K}$. Turro et al. [2] synthesized the styrene and methyl-methacrylate by dibenzyl ketones using emulsion polymerization. They concluded that this process was markedly influenced by an external magnetic field. LinTao-Cai et al. [3] have studied MFE on polyaniline (PANI) film by in situ conductivity measurements and reported that the value of conductivity for the PANI $(B p=0.7 \mathrm{~T})$ film prepared parallel to electrodes surface increases threefold as compared to that of PANI prepared in the absence of the magnetic field. H. Morika [4] reported the effect of magnetic field on the surface morphology and oxidation-reduction process in polypyrrole films.

Based on the literature survey it has been observed that the effect of low magnetic field during polymerization of aniline has been investigated with respect to change in morphology, UV spectrum, oxidation-reduction process etc. However, the effect of low magnetic field during polymerization of aniline has not been reported with respect to increased electrical conductivity. Since the changes in electrical conductivity depend on the structure and morphology of the polymer these properties have been investigated and reported in this work.

\section{Experimental}

\subsection{Sample preparation}

Chemicals: $1 \mathrm{M} \mathrm{H}_{2} \mathrm{SO}_{4}, 0.5 \mathrm{M}$ aniline and $0.5 \mathrm{M}$ potassium dichromate $\left(\mathrm{K}_{2} \mathrm{Cr}_{2} \mathrm{O}_{7}\right)$. Using the above chemicals aniline was polymerized according to the standard method [5] (sample M0). Polymerization was carried out in a glass beaker which was placed in between the pole pieces of electromagnet of field $1 \mathrm{KGauss}$ for one hour. (sample M1)

\subsection{Analysis method}

Elemental analysis of CHNS-O was performed on Vario EL III, (GmbH Germany).

Infrared spectra of samples were recorded in the range of $4000-400 \mathrm{~cm}^{-1}$ using "BRUKER" (model: vector 22) FTIR spectrophotometer.

An X-ray diffractometer (Philips Analytical X-Ray B.V., PW 1710) was used to examine PANI samples. The $\mathrm{X}$-Ray beam was $\mathrm{Cu} \mathrm{Ka}$ radiation from a sealed tube operated at $35 \mathrm{KV}$ and $25 \mathrm{~mA}$. The data were recorded from $2 \mathrm{q}=1^{\circ}$ to $40^{\circ}$.

A scanning electron microscope (Philips SEM; Model 515) was used to examine PANI powder. 
Electrical conductivity of the sample (M0 and M1) was measured at room temperature using four probes (SES-Model DEP-02) technique. Two-probe method, in which sample in the form of pellet was sandwiched between two copper electrodes, was also used for determining electrical conductivity.

\section{Results and Discussion}

The physical appearance of modified PANI designated as sample MI (in powder form) was lustrous, silvery green, very smooth and fine as compared to sample M0.

Table 1 shows the percentage of $\mathrm{C}, \mathrm{H}, \mathrm{N}, \mathrm{S}$ obtained by elemental analysis result.

Table 1

Results of elemental analysis

\begin{tabular}{|c|c|c|c|c|c|}
\hline Sample & $\begin{array}{c}\text { Designa- } \\
\text { tion }\end{array}$ & $\mathrm{C}, \%$ & $\mathrm{H}, \%$ & $\mathrm{~N}, \%$ & $\mathrm{~S}, \%$ \\
\hline $\mathrm{SO}_{4}^{-2}$ doped polyaniline (PANI) & $\mathrm{M} 0$ & 30.68 & 4.96 & 6.03 & 9.02 \\
\hline $\begin{array}{c}1 \mathrm{KG} \text { magnetic Field applied during polymerization } \\
\left(\mathrm{SO}_{4}^{-2} \text { doped PANI) }\right.\end{array}$ & $\mathrm{Ml}$ & 21.23 & 6.93 & 4.06 & 10.08 \\
\hline
\end{tabular}

Elemental analysis results show that in sample M1 hydrogen percentage has increased tremendously and percentage of sulphur introduced in polymer chain has also increased. This implies that more sites are exposed where doping of sulphur occurs. Thus in sample M1 it has been found that protonation has increased (higher percentage of hydrogen).

Table 2

Electrical conductivity values at room temperature

\begin{tabular}{|c|c|c|}
\hline \multirow{2}{*}{ Sample } & \multicolumn{2}{|c|}{ Electrical conductivity, S/cm } \\
\cline { 2 - 3 } & Four probe & Two probe \\
\hline M0 & $1.1 \cdot 10^{-2}$ & $9 \cdot 10^{-5}$ \\
\hline M1 & $1.2 \cdot 10^{0}$ & $7.3 \cdot 10^{-3}$ \\
\hline
\end{tabular}

Electrical conductivity values determined using four probes and two-probe technique were tabulated.

M1 sample shows increase in electrical conductivity of two orders of magnitude as compared to M0. The effect of the temperature variation from room temperature to $423 \mathrm{~K}$ on electrical conductivity is shown in Fig. 1 .

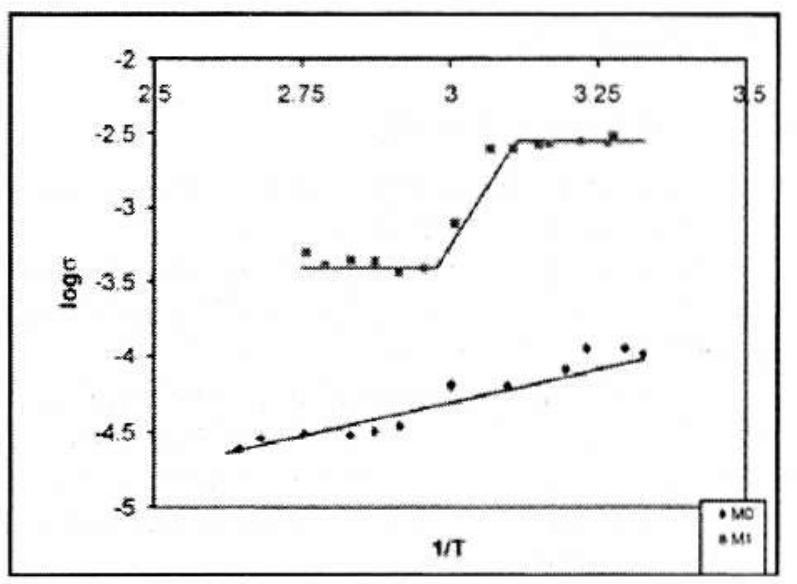

Fig. 1. Plot of $\log s$ vs. $1 / \mathrm{T} \times 10^{-3}$ for sample $\mathrm{M} 0$ and $\mathrm{Ml}$
The curve for Sample M0, showing semiconducting behavior initially up to $423 \mathrm{~K}$, thereafter shows metallic behavior. Sample M1 shows metallic behavior from room temperature onwards up to $323 \mathrm{~K}$, thereafter conductivity suddenly decreases and again remains constant showing metallic behavior throughout the temperature range.

Fig. 2 shows the IR spectra recorded for samples $\mathrm{M} 0$ and M1. Various IR bands and their assignments are shown in Table 3.

As observed from IR scans as well as from Table 3 , the band at $1493 \mathrm{~cm}^{-1}$ due to benzenoid unit is not much shifted whereas the quinoid band $\left(1599 \mathrm{~cm}^{-1}\right)$ after modification ( samples M1) shifts towards low wave number side by $25 \mathrm{~cm}^{-1}$. This indicates slight structure modification. The analysis of IR spectra shows that quinoid to benzenoid (intensity) ratio is almost constant for both samples, which is one of the parameters to explain the enhancement in electrical conductivity [6]. The region $1400-1240 \mathrm{~cm}^{-1}$ is the C-N stretching region [6]. Sample M0 shows two peaks, medium absorption at $1302 \mathrm{~cm}^{-1}$ and weak absorption at $1385 \mathrm{~cm}^{-1}$. The peak at $1302 \mathrm{~cm}^{-1}$ (medium) is strengthened enough and becomes strong as that of benzenoid and quninoid peak for sample M1. The weak absorption band at $1385 \mathrm{~cm}^{-1}$ for M0 shows intensity growth in the order of increase in applied magnetic field during polymerization i.e. sample M1 has more intensity for this band as compared to M0. The increase in intensity of the two bands observed in this $\mathrm{C}-\mathrm{N}$ stretching region in order of $\mathrm{M} 0$ and $\mathrm{M} 1$ suggests that the $\mathrm{C}-\mathrm{N}$ group vibration in PANI is facilitated much, possibly due to greater promotion or degree of exposure. Boyer et al. [7] have observed and attributed the intensity of $\mathrm{C}-\mathrm{N}$ stretching band to polymer chain length increase. They have treated this band as diagnostic of the chain length. From IR results, therefore the enhancement of intensity of $\mathrm{C}-\mathrm{N}$ stretching band at $1385 \mathrm{~cm}^{-1}$ indicates increase of continuous conjugation of polymer chain leading to exposure of hidden $\mathrm{C}-\mathrm{N}$ groups. 


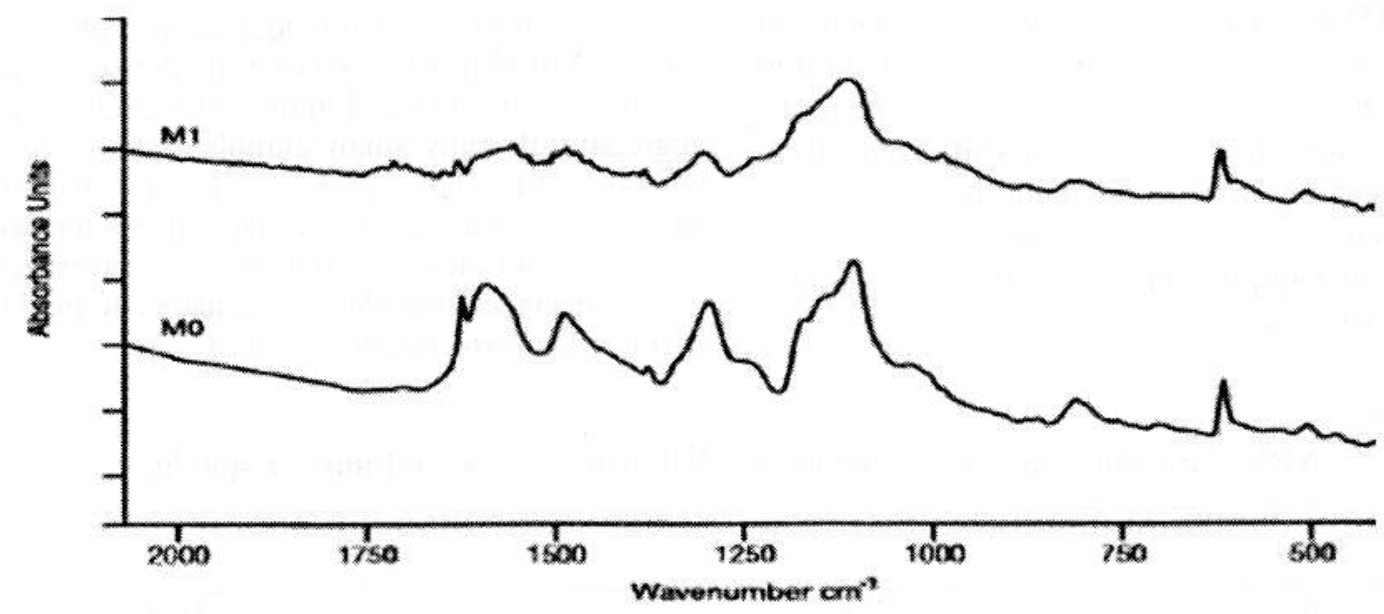

Fig. 2. IR spectra for samples $M 0$ and $M 1$

Various IR bands and their assignment

Table 3

\begin{tabular}{|c|c|c|c|c|c|c|c|c|}
\hline Sample & $\begin{array}{c}\mathrm{Q} \\
\mathrm{cm}^{-1}\end{array}$ & $\begin{array}{c}\mathrm{B}, \\
\mathrm{cm}^{-1}\end{array}$ & Q/B ratio & $\begin{array}{c}\mathrm{C}-\mathrm{N}, \\
\mathrm{cm}^{-1}\end{array}$ & $\begin{array}{c}\mathrm{N}-\mathrm{H}, \\
\mathrm{cm}^{-1}\end{array}$ & $\begin{array}{c}\text { Charge } \\
\text { delocalization } \\
\text { peak, } \mathrm{cm}^{-1}\end{array}$ & $\begin{array}{c}\mathrm{C}-\mathrm{H} \text { In plane, } \\
\mathrm{cm}^{-1}\end{array}$ & $\begin{array}{c}\mathrm{C}-\mathrm{H} \text { out plane, } \\
\mathrm{cm}^{-1}\end{array}$ \\
\hline $\mathrm{M} 0$ & 1599 & 1493 & 1.07 & 1302,1385 & 1706 & 1112,619 & 1156 & 816 \\
\hline $\mathrm{Ml}$ & 1576 & 1489 & 1.03 & 1306,1385 & 1716 & 1117,618 & 1170 & 817 \\
\hline
\end{tabular}

As suggested by Genies and Laprowaski [8], Harada et al. [9] and Ray et al. [10] the relative concentration of various $\mathrm{N}$-moities: $\mathrm{NH},+\mathrm{NH}_{2}, \mathrm{~N}=,+\mathrm{NH}=, \mathrm{C}-\mathrm{N}+-$ in polyaniline depends on the nature and percentage of doping which in turn may affect the population of charge defect centers (polarons and bipolarons) and ultimately the electrical conductivity. The $\mathrm{N}-\mathrm{H}$ stretching band, which is observed at $1706 \mathrm{~cm}^{-1}$ for sample $\mathrm{M} 0$, gets shifted to higher wave number side for M1 with increase in intensity. In this case there is also a tremendous intensity increase for $\mathrm{C}-\mathrm{N}$, and $\mathrm{NH}$ bands which may affect the population of charge defect centers or there might be increased percentage of dopant $\left(\mathrm{SO}_{4}^{-2}\right)$ introduced in PANI backbone for sample M1 as compared to M0.

The charge delocalization peaks appearing at $\sim 1114 \mathrm{~cm}^{-1}$ and $618 \mathrm{~cm}^{-1}$ which have direct correlation with conductivity [11] also show pronounced increase in M1. This suggests a greater $p$-electron delocalization in PANI material and thereby explains enhanced electrical conductivity. The band at about $1160 \mathrm{~cm}^{-1}$ is most likely to be due to in-plane $\mathrm{C}-\mathrm{H}$ bending mode of aromatic rings. In sample M1 it is well resolved in intensity. The band at $816 \mathrm{~cm}^{-1}$ is assigned to the out-of-plane $\mathrm{C}-\mathrm{H}$ bending mode for $\mathrm{SO}_{4}^{-2}$ doped polyaniline (M0). After modification, i.e. in samples M1 the band is observed at the same position, only its intensity has increased tremendously.

Figure 3 shows wide angle X-Ray diffraction pattern for samples M0 and M1. Percentage crystallinity of the sample is calculated using Manjunath's formula [12].

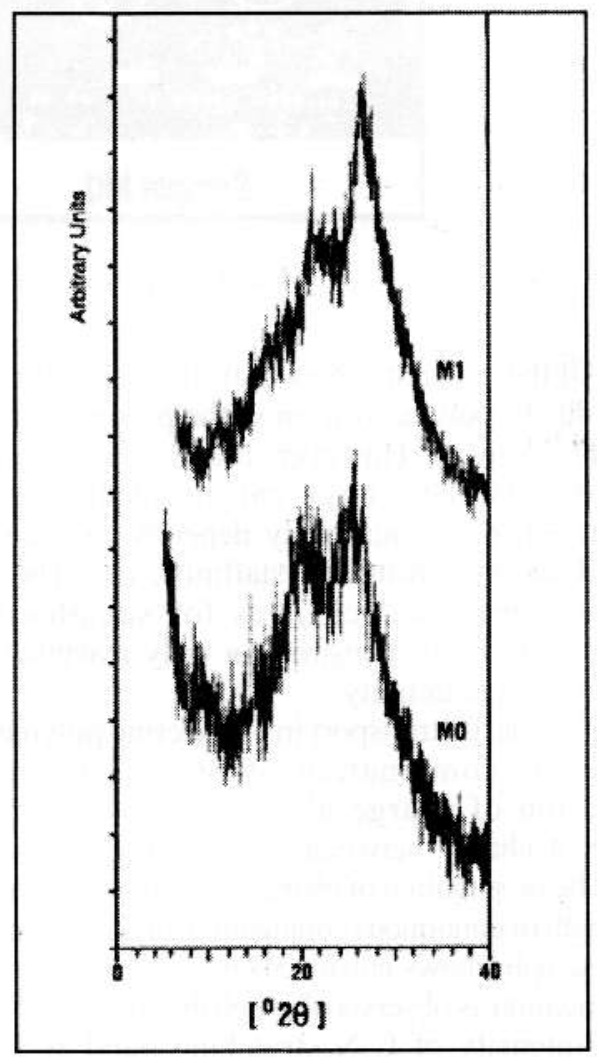

Fig. 3. Wide angle $\mathrm{X}$-ray diffraction pattern for sample M0 and M1 
The XRD pattern for M0 shows broad peaks at $2 \mathrm{q}=20^{\circ}$ and at $25.8^{\circ}$ corresponding to $(0,0,1)$ and $(1,1,0)$ reflections of PANI respectively [13]. The peaks obtained for sample Ml show slight shifts indicating slight modification in crystal structure (Table 4). Percentage crystallinity is approximately the same for sample M0 and sample M1.The $d$ spacing slightly decreases in case of sample M1.
Scanning electron microscopy photograph for sample M0 (Fig.4) is similar to the one reported by $\mathrm{S}$. Chen et al. [14] and shows that each particle is an aggregate of many small granules (shown by circle in micrograph). These granules are divided into small particles as observed in the micrograph for sample M1 (Fig 4). From these micrographs it is observed that the surface becomes smoother as the magnetic field is applied during the polymerization process.

Table 4

XRD data showing various peaks in XRD scans, \% crystallinity, $d$ spacing

\begin{tabular}{|c|c|c|c|}
\hline Sample & $2 \theta,{ }^{\circ}$ & Xc $\%$ & $d$ space, $\mathrm{A}^{\circ}$ \\
\hline M0 & $8.8,20,25.8$ & 61.4 & 3.4503 \\
\hline M1 & $9.2,19.8,26$ & 64.81 & 3.4242 \\
\hline
\end{tabular}

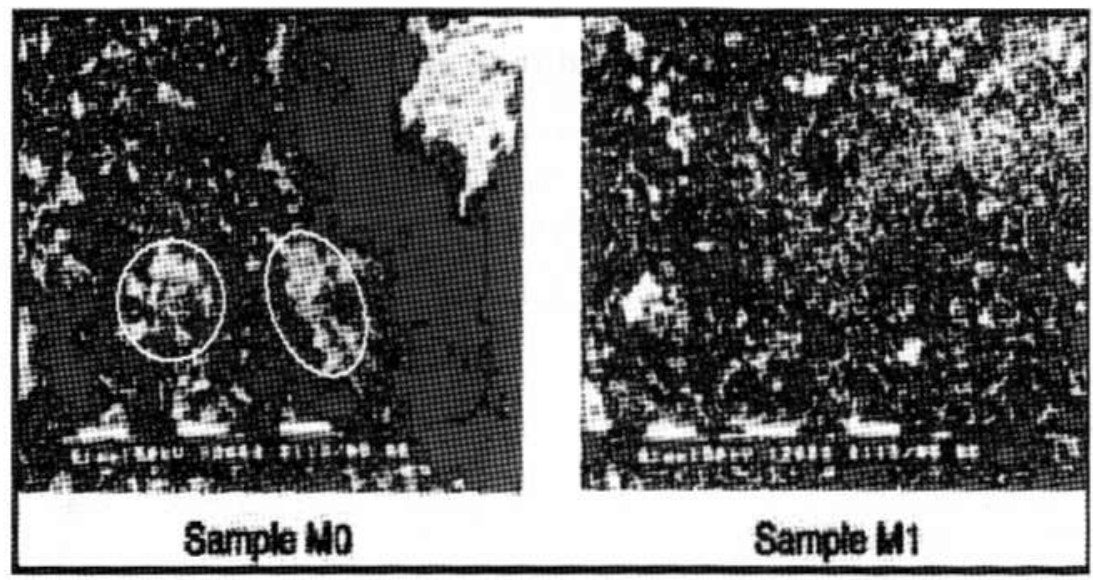

Fig 4. Scanning electron micrographs for samples M0 and M1

All these results show that there is slight structural change due to polymerization in the presence of magnetic field (sample M1). However, the electrical conductivity measurements show large enhancement. Some of the factors electrical conductivity depends on are $\mathrm{Q} / \mathrm{B}$ ratio (from IR measurement), crystallinity, etc. These factors show only marginal changes for samples $\mathrm{Ml}$, and therefore, can be responsible for only marginal increase in electrical conductivity.

The charge transport in conducting polymers occurs through the combination of two mechanisms [15] propogation of charge along the polymer chain and hopping of charge between the neighboring chains.

The propagation of charge along the chain is improved if the length of continuous conjugation along the chain increases. M1sample shows enhancement in the length of continuous conjugation as observed through the analysis of IR spectra (higher intensity of C-N stretching band at $1385 \mathrm{~cm}^{-1}$ ). Further high electrical conductivity in sample M1 can be attributed to higher number of dopant species entering the chain of sample M1 (elemental analysis supports this result).

\section{Conclusions}

Application of low magnetic field during chemical polymerization process of aniline give smooth, lustrous, silvery green, fine powder with two-order increase in electrical conductivity.

Thus the increased electrical conductivity in sample M1 is probably due to the slight increase in crystallinity with increase in chain (conjugation) length and increase in number of the dopant species.

\section{Acknowledgement}

The authors would like to express their thanks to Central Drug Research Institute (RSIC) Lucknow, for carrying out elemental C, H, N, S Analysis. The Authors also thank to Dr. Pal for Scanning Electron Microscopy (NSSLUB, NAGPUR) and Regional Sophisticated Instrumentation Centre (RSIC), Nagpur, for recording XRD and FTIR Spectra. 


\section{References}

[1] Mori K., Tabata Y.: Kogyo Kagaku Zasshi, 1970, 73, 1251.

[2] Turro N., Chow M., Ching Ch., Jung Ch.: J. Am. Chem. Soc., 1983, 105, 1572.

[3] LinTao Cai, Shi-Bing Yao and Shao-Min Zhou: J. Elecrtoanal. Chem., 1997, 421, 45.

[4] Mosika H., Yamato M., Kimura T. and Ito E.: Synth. Met., 1999, 101,33.

[5] Boyer M., Quillard S., Rebourt E., Louarn G. et al.: J. Phys. Chem., 1998, B 102, 7382.

[6] Tang J., Jing X., Wang B. and Wang F.: Synth. Met., 1988, 24,231.

[7] Boyer I., Quillard S., Rebourt E., Louran G. et al.: J. Phys. Chem., 1998, B $102,7382$.

[8] Genies E. and Laprowaski M.: Synth. Met., 1987, 21, 117.

[9] Harada I., Furukawa Y. and Ueda F.: Synth. Met., 1989, 29E, 303.

[10] Ray A., MacDiarmid A., Ginder J. and Epstein A.: Mater. Res. Soc. Symp. Proc., 1990, 173, 353.

[11] Koul S., Dhawan S. and Chandra S.: Indian J. Chem., 1997, A36, 901.

[12] Manjunath B., Venketraman A. and Stephen T.: J. Appl. Polym. Sci., 1973, 17, 1091.
[13] Han M., Cho S., Oh S. and Im S.: Synth. Met., 2002, 126, 53.

[14] Chen S. and Lee H.: Macromolecules, 1993, 26, 3254.

[15] Reynolds J., Baker C., Jolly C., Poropalic P. and Ruiz J.:

[in:] Margolies J. (Ed.), Conductive Polymers and Plastics. Chapman \& Hall, New York \& London.

\section{СИНТЕЗ ПОЛІАНІЛІНУ \\ В НИЗЬОЧАСТОТНОМУ МАГНІТНОМУ ПОЛІ, ЙОГО СТРУКТУРА ТА ЕЛЕКТРИЧНІ \\ ВЛАСТИВОСТІ}

Анотація Під дією низькочастотного магнітного поля інтенсивністю IКГаус синтезовано поліанілін. Показано, що під час синтезу магнітне поле підвичує електропровідність на два порядки. Електропровідність залежить від впорядкованості ланчюга, структури і морфології вказаного полімеру.

Ключові слова: поліанілін, хімічна полімеризачія, низькочастотне магнітне поле, електрична провідність. 